\title{
A facile way to prepare visible light driven tin oxide based photoanode and its photoelectrochemical water splitting properties
}

\author{
TIAN MengKui ${ }^{1,2 *}$, PENG WenJie ${ }^{1}$, SHANG BaiWei $^{1} \&$ TAO WenLiang ${ }^{1}$ \\ ${ }^{1}$ School of Chemistry and Chemical Engineering, Guizhou University, Guiyang 550025, China; \\ ${ }^{2}$ Department of Chemical System Engineering, School of Engineering, The University of Tokyo, Tokyo 113-8656, Japan
}

Received October 29, 2011; accepted February 27, 2012; published online July 2, 2012

\begin{abstract}
Visible light driven tin oxide based photoelectrodes were obtained using $\mathrm{SnCl}_{2} \cdot 2 \mathrm{H}_{2} \mathrm{O}$ EtOH solution on FTO by dipping and with further heat treatment in air. Photoelectrochemical measurement with three electrodes configuration under visible light irradiation $(\lambda>420 \mathrm{~nm})$ revealed that this as-prepared photoelectrode showed typical $\mathrm{n}$-type photocurrent effect and the onset potential is negative than that of $\mathrm{H}^{+} / \mathrm{H}_{2}$. XRD, UV-Vis spectrum and control experimental results revealed that the visible light driven mechanism for the tin oxide based photoanode maybe ascribed to $\mathrm{Sn}^{4+} / \mathrm{Sn}^{2+}$ transformation and the surface oxygen deficiency.
\end{abstract}

visible light driven, photocatalyst, photoanode, tin oxide, photoelectrochemical water splitting

Citation: Tian M K, Peng W J, Shang B W, et al. A facile way to prepare visible light driven tin oxide based photoanode and its photoelectrochemical water splitting properties. Chin Sci Bull, 2012, 57: 4229-4232, doi: 10.1007/s11434-012-5296-7

The development of hydrogen energy has attracted more and more attention for its renewable, high energy density per mass, and environmental benign properties [1,2]. Among these reactions and processes employed to develop hydrogen energy, photoelectrochemical (PEC) water splitting is one of the most promising ways to transfer solar energy to hydrogen as chemical energy carrier considering resource sustainability, energy consumption and environmental issues [3]. There are some special advantages for PEC, such as the presence of bias potential to improve band edge's thermodynamical potential, the separation sites for hydrogen and oxygen evolution to enhance the separation and transfer of photogenerated charge carriers, and photoelectrodes film from different ways easy to be controlled in terms of morphology of nanowire, nanonods and nanobelts [4,5]. Since PEC belongs to photocatalysis process, the most important work is to design and develop semiconductor photoelectrode materials with appropriate band gap (ca. $2.0 \mathrm{eV}$ ) to make the best use of solar energy and band edges to meet oxidizing and reducing water requirement as well as

*Corresponding author (email: tianmk@hotmail.com) high quantum yield and high stability [6,7]. Until now, these powder photocatalysts developed for photocatalysis were intensively studied and prepared to photoelectrodes by CVD, splutting, electrochemical method, electrophonic deposition, etc. These single band transition photoelectrodes from $n-\mathrm{TiO}_{2}, n-\mathrm{Fe}_{2} \mathrm{O}_{3}, n-\mathrm{ZnO}, n-\mathrm{SrTiO}_{3}$, especially these (oxy)nitrides, (oxy)sulfides $n-\mathrm{Ta}_{3} \mathrm{~N}_{5}, n-\mathrm{TaON}, n-\mathrm{LaTiO}_{2} \mathrm{~N}$, $\mathrm{CdS}$, and solid solution compounds $\mathrm{ZnO}-\mathrm{GaN}$ were intensively investigated [8-11]. Meanwhile, these single junction and multi-junction tandem cell materials and film preparation methods employed in photovoltaic cell were also greatly performed in PEC, such as $p$-GaP, $p$-GaAs, $p$-InP, InGaP, $p$-GaInP ${ }_{2} / \mathrm{GaAs} P / n, \mathrm{CICS}$, etc. [12-14]. Unfortunately, most of these materials failed to satisfy the requirements mentioned above simultaneously, and lag behind the phased target (efficiency, cost, stability) set by DOE periodically.

In these short communication, there presented a new photoelectrode prepared from just coating tin chloride on substrate of FTO to form tin oxide based film, which showed good photoanode current under visible light irradiation $(\lambda>420 \mathrm{~nm})$. The visible light driven mechanism was 
proposed based on series of control experiments and characterizations analysis.

\section{Experimental}

Photoelectrodes were fabricated by coating $\mathrm{SnCl}_{2} \cdot 2 \mathrm{H}_{2} \mathrm{O}$ (Wako Company) on FTO conductive glass (Asahi Company) or common glass and metal Ti substrate. In detail, $0.02 \mathrm{~mol} / \mathrm{L} \mathrm{SnCl}_{2} \cdot 2 \mathrm{H}_{2} \mathrm{O}$ EtOH solution was dipped onto the surface of FTO $(1.5 \mathrm{~cm} \times 5 \mathrm{~cm})$ or Ti foil $(1.5 \mathrm{~cm} \times 5 \mathrm{~cm})$ substrate, then dried in Muffin furnace at $250^{\circ} \mathrm{C}$ for $20 \mathrm{~s}$, and repeated for 5 times, finally, further annealed in Muffin furnace under $250^{\circ} \mathrm{C}$ for $1 \mathrm{~h}$ in air. The as-prepared photoelectrodes are for consequent PEC measurement directly.

The samples were identified by X-ray powder diffraction on Geiger-flex RAD-B (Rigaku; CuKa). SEM images were obtained on field-emission scanning electron microscopy (FE-SEM; S-4700, Hitachi). UV-Vis diffuse reflectance spectrum was recorded by a spectrophotometer (JASCO, V-670).

The photoelectrochemical measurement was performed by three-electrodes configuration mode consisting of a working electrode (as-prepared electrode), a counter electrode ( $\mathrm{Pt}$ mesh) and a reference electrode $(\mathrm{Ag} / \mathrm{AgCl})$ as well as electrolyte $\left(0.1 \mathrm{~mol} / \mathrm{L}\right.$ aqueous $\mathrm{Na}_{2} \mathrm{SO}_{4}$ solution $)$, and the $\mathrm{pH}$ of the electrolyte solution was adjusted to 4.0 by $0.1 \mathrm{~mol} / \mathrm{L}$ $\mathrm{H}_{2} \mathrm{SO}_{4}$ solution. The bias potential on working electrode was controlled by a Potentiostat (HSV-100), and transferred into RHE by the equation of $\mathrm{RHE}=V_{\mathrm{Ag} / \mathrm{AgCl}} \times 0.059 \times \mathrm{pH}+$ $E^{\circ}{ }_{\mathrm{Ag} / \mathrm{AgCl}}, E_{\mathrm{Ag} / \mathrm{AgCl}}^{\circ}=0.196 \mathrm{~V}$ vs. NHE. The solution was purged with high purity Ar gas for over 10 min before the measurements. The electrode was irradiated through silicon glass window by a Xe lamp (300 W, Cermax) fitted with a cut-off filter (Hoya L-42) to block light of wave length less than $420 \mathrm{~nm}$.

\section{Results and discussion}

\subsection{PEC water splitting activities}

The photocurrent effect under visible light irradiation $(\lambda>$ $420 \mathrm{~nm}$ ) for the as-prepared photoelectrode from coating $\mathrm{SnCl}_{2} \cdot 2 \mathrm{H}_{2} \mathrm{O}$ on FTO is shown in Figure 1 . In Figure 1, it can be seen that this FTO substrate without any coating showed no detectable photocurrent effect, while this FTO with coating presented obvious photocurrent. Under positive bias potential, there showed obvious anodic current density with about $\mathrm{mA} \mathrm{cm}{ }^{-2}$ level. Consequently, this photoelectrode acted as photoanode (a typical N-type photocurrent effect), on which took place the oxidation of water by the photo-generated holes, while the photo-generated pair electrons transferred from the bulk to the counter electrode through external circuit to involve the reduction of water [15]. Moreover, the onset potential for this photoanode, corresponding to the flat band potential of a semiconductor,

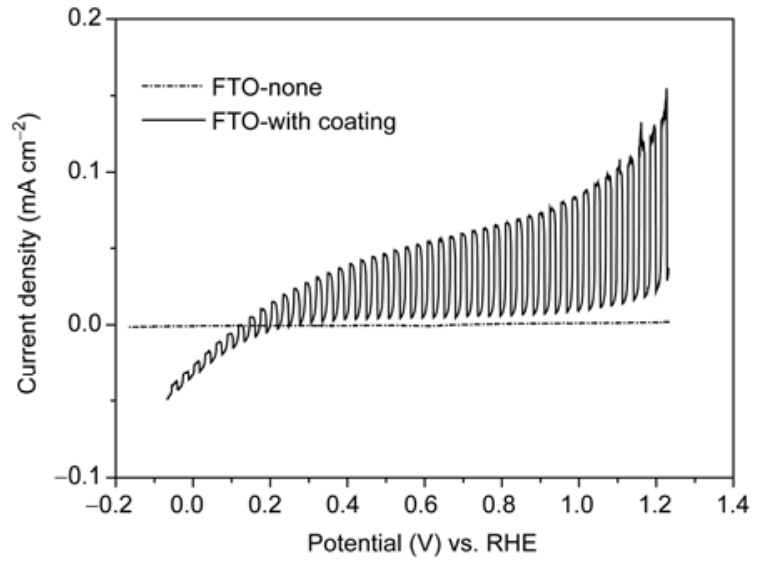

Figure 1 The photocurrent effect ( $I-V$ curve) for as-prepared photoelectrode on FTO under visible light irradiation $(\lambda>420 \mathrm{~nm})$. Scanning from right to left with rates: $5 \mathrm{mV} \mathrm{s}^{-1}$; intermediate cutoff by a shuttle with $3 \mathrm{~s}$ periodically. The similar phenomenon also occurred on metal Ti foil substrate.

which locates near to the bottom of the conduction band for a $\mathrm{N}$-type semiconductor, is negative than that of $0 \mathrm{~V}$ vs. NHE, which indicates that this photoelectrode can split water into $\mathrm{H}_{2}$ and $\mathrm{O}_{2}$ without any bias potential [16].

Furthermore, it is worth noting that the photocurrent effect under visible light irradiation on these coating with $\mathrm{SnCl}_{2} \cdot 2 \mathrm{H}_{2} \mathrm{O}$ EtOH on FTO or Ti foil is reproducible.

As for PEC measurement, except for the amount of current density, the stability is important to identify their properties. As for this prepared photoelectrode, their stability property is shown in Figure 2 ( $I-T$ curve). It can be seen that after about $1.5 \mathrm{~h}$ irradiation, the current recovered to a high level. Also from this $I-T$ curve, we could deduce that its turn of number (TON) is about 4 , which indicated that the reaction ran photocatalytically.

The IPCE efficiency at $420 \mathrm{~nm}$ (with wavelength band of $10 \mathrm{~nm}$ ) is about $2.3 \%$ from the following equation:

$$
\begin{aligned}
& \operatorname{IPCE}(\lambda)=\frac{\text { Electrons }\left(\mathrm{cm}^{2} \mathrm{~s}^{-1}\right)}{\text { Photos }\left(\mathrm{cm}^{2} \mathrm{~s}^{-1}\right)} \\
&=\frac{\left|j_{\mathrm{ph}}\left(\mathrm{mA} \mathrm{cm}^{-2}\right)\right| \times 1239.8(V \times \mathrm{nm})}{P_{\text {mono }}\left(\mathrm{mW} \mathrm{cm}^{-2}\right) \times \lambda(\mathrm{nm})}, \\
& p_{\text {mono }}\left(\mathrm{mW} \mathrm{cm}^{-2}\right)=\frac{I_{\text {photodiode }}(\mathrm{mA})}{S_{\text {sensor intersity }}\left(\mathrm{mA} \mathrm{W}^{-1}\right)},
\end{aligned}
$$

where $j_{\mathrm{ph}}$ is the photocurrent density at certain wavelength $\lambda$ $(\mathrm{nm})$, and $I_{\text {photodiode }}$ is the irradiation intensity obtained experimentally at the wavelength, while $S_{\text {sensor intensity }}$ is a set constant of the instrument.

\subsection{The visible light driven mechanism}

In order to minimize the effect from substrate FTO (fluorine doped $\mathrm{SnO}_{2}$ ) on their measurement of XRD pattern and $\mathrm{UV}-\mathrm{V}$ is spectrum, there prepared sample on common glass 


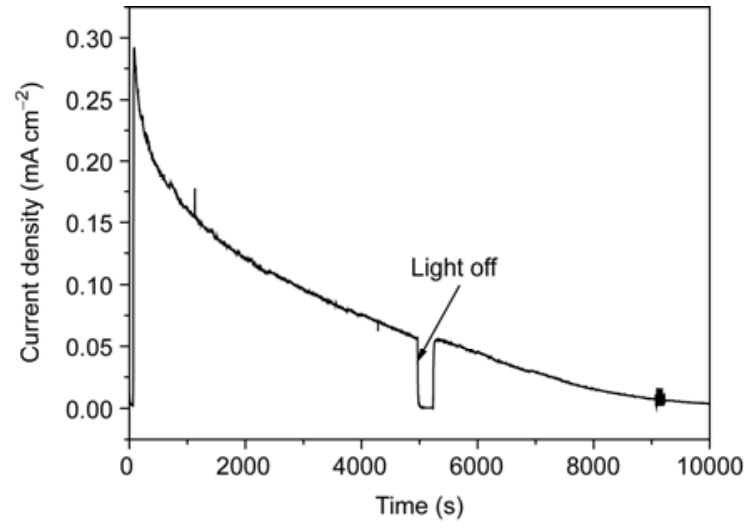

Figure 2 The $I-T$ curve for as-prepared photoelectrode on FTO under visible light irradiation $(\lambda>420 \mathrm{~nm})$. Bias potential $0.6 \mathrm{~V}$ vs. $\mathrm{Ag} / \mathrm{AgCl}$.

surface with the same procedure as described above. The XRD pattern for this sample prepared on common glass is shown in Figure 3. It can be seen that although the crystalline is poor, the main phase for as-prepared sample is $\mathrm{SnO}_{2}$ obviously. In order to further identify the materials obtained by this coating procedure, there carried out preparation of powder sample by drying $0.02 \mathrm{~mol} / \mathrm{L} \mathrm{SnCl}_{2} \cdot 2 \mathrm{H}_{2} \mathrm{O} \mathrm{EtOH}$ solution at $250^{\circ} \mathrm{C}$ in air, then measured its PEC properties under visible light. The XRD pattern for the powder sample obtained is pure $\mathrm{SnO}_{2}$, and there was no photocurrent effect on the photoelectrode from the powder prepared by electrophoretic method.

The UV-Vis diffuse reflectance spectrum for this as-prepared sample on common glass is shown in Figure 4. From Figure 4, it can be seen that there are two absorption edges for this sample coated with $\mathrm{SnCl}_{2} \cdot 2 \mathrm{H}_{2} \mathrm{O}$. One is located at about $380 \mathrm{~nm}$ and the other is at about $720 \mathrm{~nm}$. While the appearance of the as-prepared sample showed some degree of brown and yellow color. The near violet absorption edge is near to that of bulk glass, and the visible light region may be regarded as the absorption edge of the visible light driven tin oxide. The SEM images for this FTO coated with $\mathrm{SnCl}_{2} \cdot 2 \mathrm{H}_{2} \mathrm{O}$ are shown in Figure 5. SEM images revealed that the coating surface is not so average and smooth, and the thickness of coating layer is about $40 \mu \mathrm{m}$ (Figure 5(b)).

$\mathrm{SnO}_{2}$ is a well-known wide band gap semiconductor (about $3.6-3.8 \mathrm{eV}$ ), and is usually used as transparent

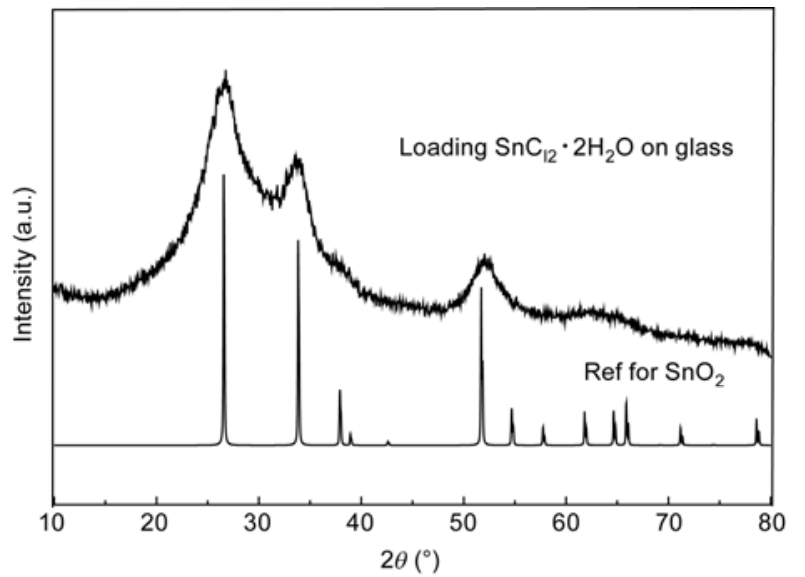

Figure 3 The XRD pattern for as-prepared sample of coating $\mathrm{SnCl}_{2} \cdot 2 \mathrm{H}_{2} \mathrm{O}$ $\mathrm{EtOH}$ on common glass substrate.

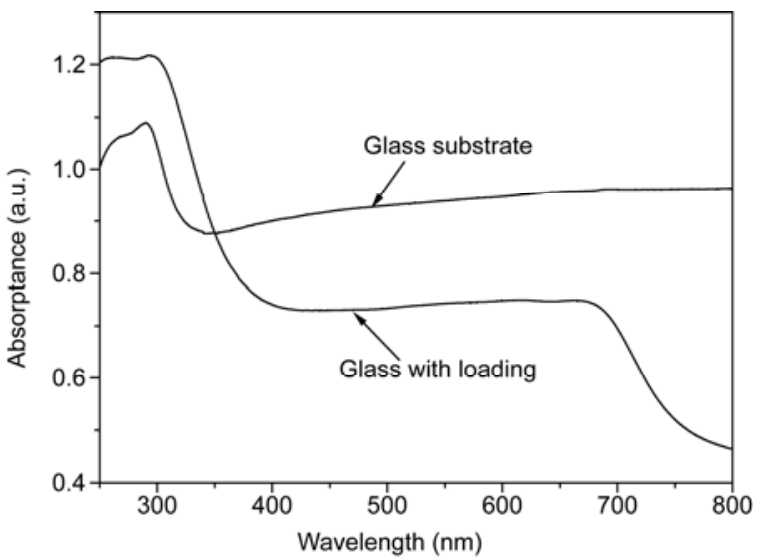

Figure 4 The UV-Vis spectra for as-prepared sample coating with $\mathrm{SnCl}_{2} \cdot 2 \mathrm{H}_{2} \mathrm{O}$ EtOH on common glass substrate.

conductive glass, gas sensors and photocatalyst [17]. As a photocatalyst, one way is to use its low conduction band edge to facilitate the transfer of photo-generated electrons in complex photocatalysts $\left(\mathrm{TiO}_{2}-\mathrm{SnO}_{2} ; \mathrm{ZnO}-\mathrm{SnO}_{2}\right)[18,19]$, the other is to modify its morphology into nanobelt, Vshape, nanostructure [20]. Its wide band gap results from its electronic structure, which consists of $\mathrm{O} 2 \mathrm{p}$ contributing to the top of valence band, and $S n 5 s^{2} 5 \mathrm{p}^{2}$ to the bottom of conduction band. While in this visible light driven $\mathrm{Sn}^{2+}$ including

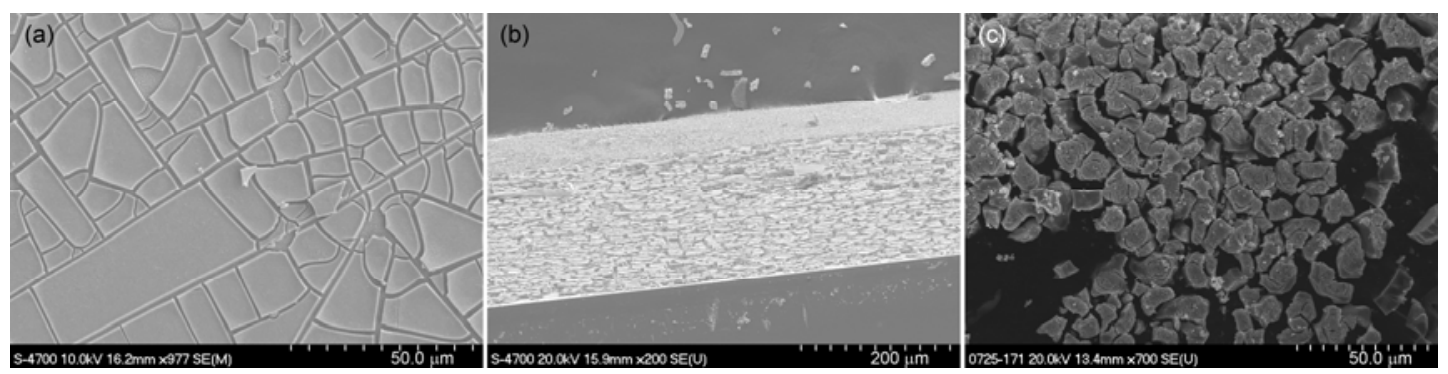

Figure 5 SEM images for this coating with $\mathrm{SnCl}_{2} \cdot 2 \mathrm{H}_{2} \mathrm{O}$ EtOH on FTO. (a) From the surface; (b) from the cross side; (c) powder from the coating layer. 
photocatalysts $\mathrm{Sn}_{2} \mathrm{Nb}_{2} \mathrm{O}_{7}\left(\mathrm{SnNb}_{2} \mathrm{O}_{6}\right)$, and $\mathrm{Sn}^{2+}$ ion-exchange $\mathrm{Sn}^{2+} / \mathrm{K}_{4} \mathrm{Nb}_{6} \mathrm{O}_{17}(50 \%), \mathrm{Sn}^{2+} / \mathrm{KTiNbO}_{5}$ (100\% exchanged), it was proposed that the $\mathrm{Sn} 5 \mathrm{~s}^{2}$ contributes to the top of the valence band, and is located in about $0.7-1.4 \mathrm{eV}$ negative than that of $\mathrm{O} 2 \mathrm{p}$, leading to the decrease of their band gap $[21,22]$. Consequently, for the current visible light driven photoelectrode from coating $\mathrm{SnCl}_{2} \cdot 2 \mathrm{H}_{2} \mathrm{O} \mathrm{EtOH}$, it is believed that the binary valence $\left(\mathrm{Sn}^{4+} / \mathrm{Sn}^{2+}\right)$ from valence electron of $S n 5 s^{2} 5 p^{2}$ contributed mainly to its visible light driven mechanism, which can be supported by the control experiment results of drying $\mathrm{SnCl}_{2} \mathrm{EtOH}$ solution in air. Since the redox potential for $\mathrm{Sn}^{4+} / \mathrm{Sn}^{2+}$ is $0.154 \mathrm{~V}$ vs. NHE, located at more negative than that of oxidation of $\mathrm{H}_{2} \mathrm{O}$, there showed poor stability in the photoelectrode (Figure 2) for the photocorrsion reaction of oxidation of $\mathrm{Sn}^{2+}$ is easier to happen than expected oxidation of water into $\mathrm{O}_{2}$. Furthermore, since $\mathrm{SnO}_{2}$ is usually regarded as an oxygen-deficient n-type semiconductor, oxygen-deficiency is widely recognized as a mechanism to many visible light driven photocatalysts [23]. So for the current visible light driven photoelectrode from coating $\mathrm{SnCl}_{2} \cdot 2 \mathrm{H}_{2} \mathrm{O}$ alcohol solution, the visible light driven mechanism is mainly ascribed to the combination of the $\mathrm{Sn}^{2+}$ doped into the $\mathrm{SnO}_{2}$ and the oxygen deficiency on the surface.

\section{Conclusion}

In this article, there presented a facile way to prepare visible light driven tin oxide based photoanode just coating $\mathrm{SnCl}_{2}$. $2 \mathrm{H}_{2} \mathrm{O}$ EtOH on FTO or metal Ti substrate. Control experimental results and characterizations indicated that the visible light driven mechanism for the as-prepared photoanode mainly results from the binary valence $\left(\mathrm{Sn}^{4+} / \mathrm{Sn}^{2+}\right)$ transformation and surface oxygen deficiency. Further work focusing on the improvement of their current density and stability, as well as the visible light driven mechanism in detail is under way.

This work was supported by the National Natural Science Foundation of China (21103028) and the Key Program of Society Development of Guizhou Province (SZ (2008)3008), the Key Program of Science and Technology of Guiyang City ((2008)014) and the Cultivating Project of Guizhou Province (024).
1 Winter C J. Hydrogen energy-abundant, efficient, clean: A debate over the energy-system-of change. Int J Hydrogen Energy, 2009, 34: 1-52

2 Lewis N S. Toward cost-effective solar energy issue. Science, 2007, 315: 798-801

3 Grätzel M. Photoelectrochemical cells. Nature, 2001, 414: 338-344

4 HoChbaum A I, Yang P D. Semiconductor nanowires for energy conversion. Chem Rev, 2010, 110: 527-546

5 Lopez-Luke T, Wolcott A, Xu L P, et al. Nitrogen-doped and CdSe quantum-dot-sensitized nanocrystalline $\mathrm{TiO}_{2}$ films for solar energy conversion applications. J Phys Chem C, 2008, 112: 1282-1292

6 Chen X B, Shen S H, Guo L J, et al. Semiconductor-based photocatalytic hydrogen generation. Chem Rev, 2010, 110: 6503-6570

7 Osterloh F E. Inorganic materials as catalysts for photochemical splitting of water. Chem Mater, 2008, 20: 35-54

8 Gupta S M, Tripathi M. A review of $\mathrm{TiO}_{2}$ nanoparticles. Chin Sci Bull, 2011, 56: 1639-1657

9 Masaaki K, Michikazu H. Heterogeous photocatalytic cleavage of water. J Mater Chem, 2010, 20: 627-641

10 Walter M G, Warren E L, Mckone J R, et al. Solar water splitting cells. Chem Rev, 2010, 110: 6446-6473

11 Maeda K, Domen K. Solid solution of GaN and $\mathrm{ZnO}$ as a stable photocatalyst for overall water splitting under visible light. Chem Mater, 2010, 22: 612-623

12 Khaselev O, Turaer J A. A monolithic photovoltaic-photoelectrochemical device for hydrogen production via water splitting. Science, 1998, 280: 425-427

13 Deutsch T G, Koval C A, Turner J A. III-V nitride epilayers for photoelectrochemical water splitting: GaPN and GaAsPN. J Phys Chem B, 2006, 110: 25297-25307

14 Aryal K, Pantha B N, Li J, et al. Hydrogen generation by solar water splitting using P-InGaN photoelectrochemcial cells. Appl Phys Lett, 2010, 96: 1-3

15 Arthur J, Nozik R M. Physical chemsitry of semiconductor-liquid interfaces. J Phys Chem, 1996, 100: 13061-13078

16 Carl A K, Jason N H. Electron transfer at semiconductor electrodeliquid electrolyte interfaces. Chem Rev, 1992, 92: 411-433

17 Batzill M, Diebold U. The surface and materials science of tin oxide. Progr Surface Sci, 2005, 79: 47-54

18 Nur H, Misnon I I, Wei L K. Stannic oxide-titanium dioxide coupled semiconductor photocatalyst loaded with polyaniline for enchanced photocatalytic oxidation of 1-octene. Int J Photoenergy, 2007, 2007: 1-6

19 Li J H, Zhang J Z. Optical properties and applications of hybrid semiconductor. Coordin Chem Rev, 2009, 253: 3015-3041

20 Luo S H, Fan J Y, Liu W L, et al. Systhesis and low-temperature photoluminescence properties of $\mathrm{SnO}_{2}$ nanowires and nanobelts. Nanotechnology, 2006, 17: 1695-1699

21 Hosogi Y, Kato H, Kudo A. Photocatalytic activities of layered titanates and niobates ion-exchanged with $\mathrm{Sn}^{2+}$ under visible light irradiation. J Phys Chem C, 2008, 112: 17678-17682

22 Hosogi Y, Shimodaira $\mathrm{Y}$, Kato $\mathrm{H}$, et al. Role of $\mathrm{Sn}^{2+}$ in the band structure of $\mathrm{SnM}_{2} \mathrm{O}_{6}$ and $\mathrm{Sn}_{2} \mathrm{M}_{2} \mathrm{O}_{7}(\mathrm{M}=\mathrm{Nb}$ and $\mathrm{Ta})$ and their photocatalytic properties. Chem Mater, 2008, 20: 1299-1307

23 Linsebigler A L, Lu G Q, Yates J T. Photocatalysis on $\mathrm{TiO}_{2}$ surfaces: Principles, mechanisms, and selected results. Chem Rev, 1995, 95: $735-758$

Open Access This article is distributed under the terms of the Creative Commons Attribution License which permits any use, distribution, and reproduction in any medium, provided the original author(s) and source are credited. 